\title{
Gold nanoparticles as a potent radiosensitizer in neutron therapy
}

\author{
Eun Ho Kim ${ }^{1}$, Mi-Sook Kim², Hyo Sook Song ${ }^{3}$, Seung Hoon Yoo ${ }^{1}$, Sei Sai ${ }^{4}$, Kwangzoo \\ Chung $^{5}$, Jiwon Sung ${ }^{3}$, Youn Kyoung Jeong ${ }^{6}$, YunHui $\mathbf{J o}^{3}$ and Myonggeun Yoon ${ }^{3}$ \\ ${ }^{1}$ Division of Heavy Ion Clinical Research, Korea Institute of Radiological and Medical Sciences, Seoul, Korea \\ ${ }^{2}$ Department of Radiation Oncology, Korea Institute of Radiological and Medical Sciences, Seoul, Korea \\ ${ }^{3}$ Department of Bio-convergence Engineering, Korea University, Seoul, Korea \\ ${ }^{4}$ Department of Basic Medical Sciences for Radiation Damages, National Institute of Radiological Sciences, Chiba, Japan \\ ${ }^{5}$ Department of Radiation Oncology, Samsung Medical Center, Seoul, Korea \\ ${ }^{6}$ Research Center for Radiotherapy, Korea Institute of Radiological and Medical Sciences, Seoul, Korea
}

Correspondence to: Myonggeun Yoon, email: radioyoon@korea.ac.kr Mi-Sook Kim, email: mskim@kirams.re.kr

Keywords: gold nanoparticles, neutron therapy, radiosensitizer, cancer, $y$-ray

Received: May 23, 2017 Accepted: July 25, $2017 \quad$ Published: August 03, 2017

Copyright: Kim et al. This is an open-access article distributed under the terms of the Creative Commons Attribution License 3.0 (CC BY 3.0), which permits unrestricted use, distribution, and reproduction in any medium, provided the original author and source are credited.

\section{ABSTRACT}

The purpose of this study was to investigate the potential of gold nanoparticles as radiosensitizer for use in neutron therapy against hepatocellular carcinoma.

The hepatocellular carcinoma cells lines Huh7 and HepG2 were irradiated with Y and neutron radiation in the presence or absence of gold nanoparticles. Effects were evaluated by transmission electron microscopy, cell survival, cell cycle, DNA damage, migration, and invasiveness.

Gold nanoparticles significantly enhanced the radiosensitivity of Huh7 and HepG2 cells to y-rays by $1.41-$ and 1.16 -fold, respectively, and by 1.80 - and 1.35 -fold to neutron radiation, which has high linear energy transfer. Accordingly, exposure to neutron radiation in the presence of gold nanoparticles induced cell cycle arrest, DNA damage, and cell death to a significantly higher extent, and suppressed cell migration and invasiveness more robustly. These effects are presumably due to the ability of gold nanoparticles to amplify the effective dose from neutron radiation more efficiently.

The data suggest that gold nanoparticles may be clinically useful in combination therapy against hepatocellular carcinoma by enhancing the toxicity of radiation with high linear energy transfer.

\section{INTRODUCTION}

Malignant tumors are a leading cause of mortality worldwide [1]. Almost $80 \%$ of patients with hepatocellular carcinoma (HCC) are from the Asia-Pacific region. HCCs are usually treated by surgical resection, with 5 -year survival rates of $30-70 \%[2,3]$. However, surgery is suitable for fewer than $16 \%$ of patients, and conventional chemotherapy does not significantly improve clinical outcomes in patients with advanced tumors [4]. Radiotherapy may provide sustained local control in certain patients, an effect that may be enhanced by radiosensitizing agents [5]. In general, ionizing radiation kills cancer cells in two ways, depending on the energy of the radiation.
Low-linear energy transfer (LET) radiation, such as $\mathrm{X}$-rays, kills cells by generating reactive oxygen species (ROS) and free radicals [6], whereas high-LET radiation, such as neutrons, kills cells by nuclear interactions [7]. Because malignant tumors tend to have low oxygen levels, making them relatively unaffected by low-LET radiation [8], neutron radiation may be more appropriate. Indeed, neutron radiation has been shown to be more effective than low-LET radiation in treating salivary gland carcinomas, adenoid cystic carcinomas, and certain brain tumors, especially high-grade gliomas [7, 9]. In addition, neutron therapy generally requires shorter treatment cycles, as only one-third of the effective dose of neutrons is required to kill the same number of cancer cells as photons $[7,8]$. 
Despite the promise of neutron therapy, it is still necessary to specifically increase toxicity to tumor cells while minimizing side effects in normal cells [10]. Recently, nanotechnology has provided both opportunities and challenges to improve cancer diagnosis and treatment [11], including the development of nanoscale radiosensitizers. In particular, gold nanoparticles, which passively accumulate in tumors [12-14], have shown promising results as radiosensitizers [15]. Although nanoparticles could result in damage to organelles and/ or DNA, apoptosis, mutagenesis, and protein up/down regulation, the toxicity due to gold nanoparticles has been found to be minimal [16]. The advantages of gold nanoparticles include their high mass energy absorption due to a high atomic number $(Z=79)$ [17], their relatively easy synthesis, and their ready functionalization [18]. In general, biological molecules such as DNA and RNA are also capable of being functionalized by GNPs. This can be achieved by taking advantage of the electrostatic interactions between GNPs and their targeted biological molecule, thereby creating GNP bio-conjugates. Although gold nanoparticles were shown to act as radiosensitizers for X-rays, the effects of these particles on radiosensitivity have not been examined over a wide range of incident types of therapeutic radiation. This study therefore investigated the ability of gold nanoparticles to enhance the toxicity to neutron radiation of HCC cell lines in vitro. This study also attempted to determine the mechanisms driving the cellular response to high-LET uncharged radiation (neutrons) and low-LET radiation (photons).

\section{RESULTS}

Gold nanoparticles were taken up by HepG2 and Huh7 cells within $24 \mathrm{~h}$ (Figure 1A). Fluorescently labeled nanoparticles were similarly taken up, accumulating near the nuclear membrane and in the cytoplasm (Figure 1B). Co-staining indicated that most nanoparticles accumulated in the endoplasmic reticulum (Figure 1B). Cells irradiated in the presence of gold nanoparticles had a significantly lower survival rate than cells irradiated in the absence of nanoparticles (Figure 2A). The parameters of the linear quadratic fitting of survival curves and the doses required to reduce survival to $10 \%$ are shown in the tables (Tables 1,2).

To test if caspase activation, which leads to apoptosis induction, is the main cause of GNP-induced radiosensitization, Huh7 and HepG2 cells were incubated in the presence or absence of the apoptosis inhibitor z-VAD-fmk, which inactivates caspases, and the results of clonogenic assays were analyzed. Treatment with z-VAD-fmk significantly blocked the increased apoptosis of these cells induced by GNP plus radiation (Figure 2B). Irradiation of the two HCC cell lines in the presence of gold nanoparticles significantly increased the numbers of apoptotic cells (Figure 2C and Table 3). Compared with radiation alone, combined treatment enhanced PARP1 fragmentation and reduced the expression of the antiapoptotic protein Bcl-2 (Figure 2D), confirming that gold nanoparticles enhanced apoptosis. In addition, the effect of gold nanoparticles was more pronounced with neutrons than with $\gamma$ radiation.

GNP treatment itself did not alter cell cycle distribution at $24 \mathrm{~h}$ (Figure 3). Conversely, $\gamma$-ray or neutron radiation alone markedly increased the number of cells in G2/M and reduced the cells in G1 (Figure 3A) [19-21], while also reducing the number of cells in S-phase, albeit to a lesser extent than the reduction in G1 phase. Combination treatment of both cell lines caused the greatest accumulation of cells in $\mathrm{G} 2 / \mathrm{M}$ phase, suggesting efficient induction of cell cycle arrest in both. Similarly, western blotting showed that radiation alone or combined treatment induced significant accumulation of cyclin B, a key regulator of G2/M transition (Figure 3B). Although not statistically significant, the ability of GNPs to alter cell cycle distribution was more pronounced with neutrons than with $\gamma$ radiation (Figure 3).

Damage to DNA foci occurred within $30 \mathrm{~min}$ and $6 \mathrm{~h}$ after treatment of the HCC cell lines with and without GNPs, respectively, with gamma radiation (5 Gy) or neutron radiation (5 GyE), with this damage persisting for up to $24 \mathrm{~h}$. More foci were observed after neutron than after $\gamma$-radiation of GNP-treated cells (Figure 4A, 4B and Supplementary Figure 1A, 1B. In addition, sustained expression of phosphorylated $\mathrm{H} 2 \mathrm{AX}$, a marker of DNA damage response, by cells treated with irradiation plus GNPs was observed $24 \mathrm{~h}$ later, both by immunofluorescence (Figure 4A, 4B) and western blotting (Figure 4C).

The combination of GNPs and radiation significantly inhibited cell migration and invasion (Figure 5A, 5B), as well as suppressing the expression of proteins, including vimentin and MMP-9, that drive epithelial-mesenchymal transition and invasion (Figure 5C). In particular, vimentin expression was markedly reduced in cells treated with GNPs and neutron radiation (Figure 5D). GNP treatment itself did not alter cell migration or invasion. In addition, irradiation in the presence of GNPs reduced stellate structures that are a hallmark of invasive cells (Figure 5E). These effects were more pronounced with neutron radiation than with $\gamma$-rays.

\section{DISCUSSION}

GNPs are promising nanoscale drug carriers, radiosensitizers, and imaging contrast enhancers for cancer diagnosis and therapy [11, 15, 22-24]. These applications are based on size-dependent passive targeting, and on the physical and chemical properties of gold [11, 12, 22, 25], which include dose enhancement, as seen in Monte Carlo simulations [6, 26-29]. Indeed, the radiobiological effects of GNPs have been extensively investigated for various 
Table 1: Linear quadratic fitting parameters $\alpha$ and $\beta$ for survival curves in cells irradiated in the presence or absence of gold nanoparticles (GNP) and incubated for 14 days

\begin{tabular}{clll}
\hline Cell type & Treatment & $\boldsymbol{\alpha}\left(\mathbf{G y}^{-1}\right)$ & $\boldsymbol{\beta}\left(\mathbf{G y}^{-1}\right)$ \\
\hline \multirow{3}{*}{ Huh7 } & $\gamma$-ray & $0.106 \pm 0.379$ & $0.029 \pm 0.055$ \\
& $\gamma$-ray + GNP & $0.154 \pm 0.399$ & $0.057 \pm 0.059$ \\
& Neutron & $0.138 \pm 0.378$ & $0.029 \pm 0.055$ \\
& Neutron + GNP & $0.525 \pm 0.413$ & $0.021 \pm 0.061$ \\
\hline \multirow{3}{*}{ HepG2 } & $\gamma$-ray & $0.004 \pm 0.375$ & $0.040 \pm 0.053$ \\
& $\gamma$-ray + GNP & $0.134 \pm 0.401$ & $0.034 \pm 0.059$ \\
& Neutron & $0.043 \pm 0.375$ & $0.036 \pm 0.055$ \\
& Neutron + GNP & $0.093 \pm 0.367$ & $0.059 \pm 0.053$ \\
\hline
\end{tabular}
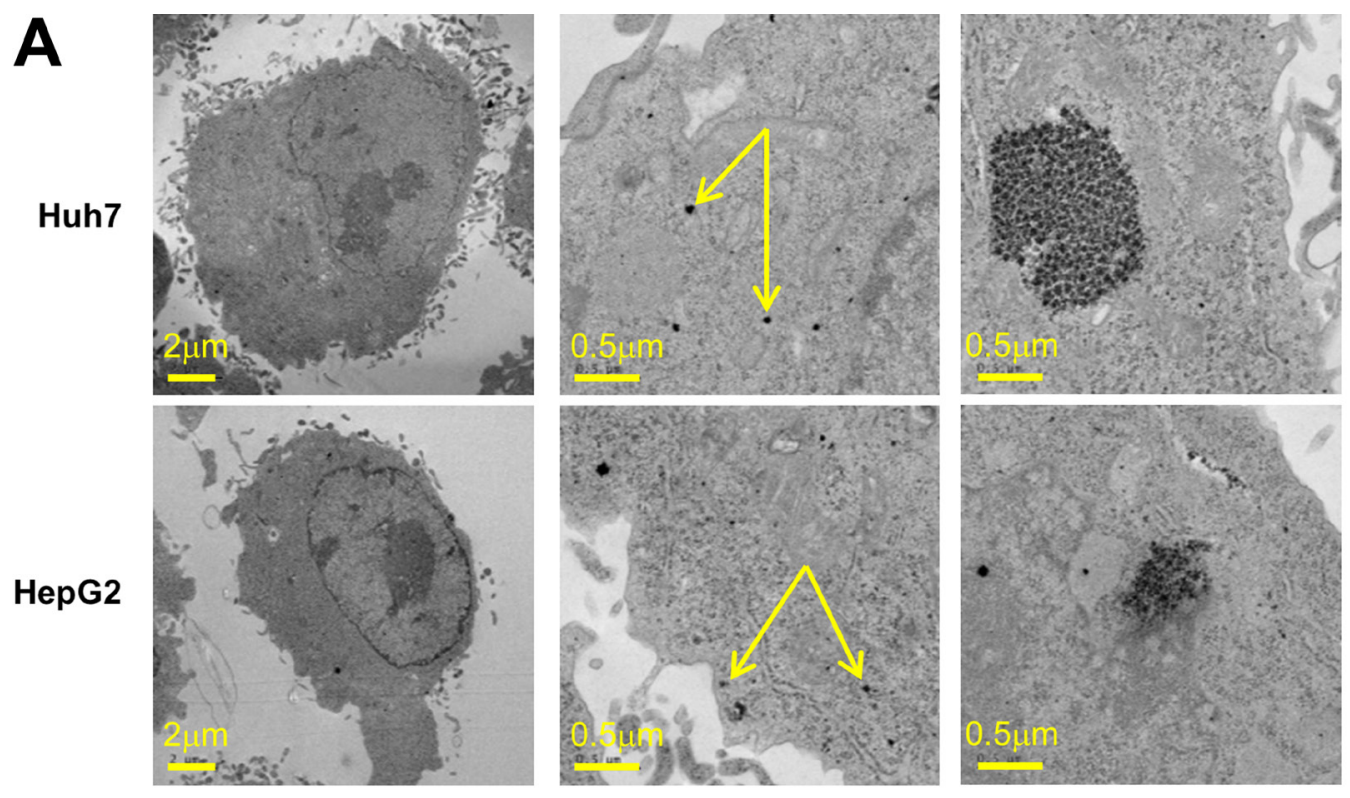

B
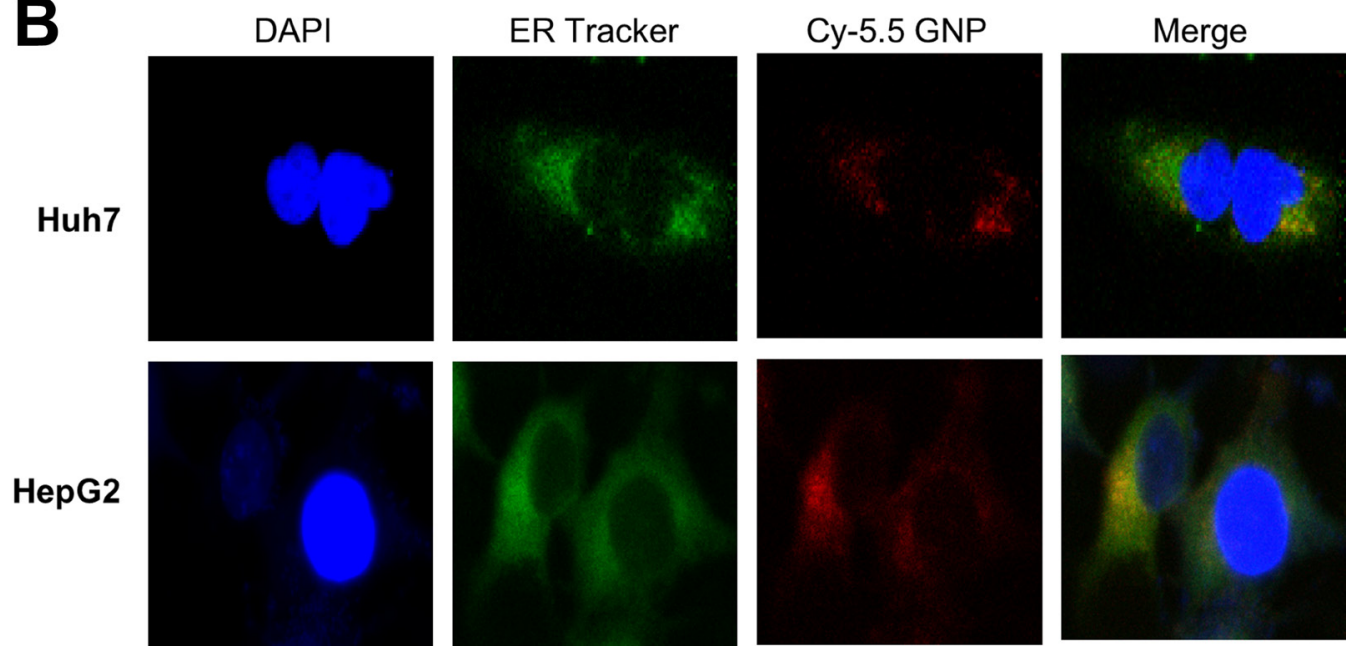

Figure 1: Intracellular localization of $5 \mathbf{~ n m}$ gold particles. (A) Transmission electron microscopy (80kV) of monodispersed $5 \mathrm{~nm}$ gold nanoparticles. (B) Huh7 and HepG2 cells incubated for $24 \mathrm{~h}$ with $1 \mathrm{mM}$ Cy5.5-labeled gold nanoparticles, and stained with specific dyes for nuclei (DAPI) and endoplasmic reticulum. 
Table 2: Radiation dose needed to kill $90 \%$ of cells (D10) in the presence or absence of gold nanoparticles (GNP)

\begin{tabular}{cccc}
\hline Cell type & Radiation & D10 without GNP & D10 with GNP \\
\hline \multirow{2}{*}{ Huh7 } & $\gamma$-ray & $7.26 \mathrm{~Gy}$ & $5.14 \mathrm{~Gy}$ \\
& Neutron & $6.84 \mathrm{~Gy}$ & $3.81 \mathrm{~Gy}$ \\
\multirow{2}{*}{ HepG2 } & $\gamma$-ray & $7.53 \mathrm{~Gy}$ & $6.49 \mathrm{~Gy}$ \\
& Neutron & $7.42 \mathrm{~Gy}$ & $5.50 \mathrm{~Gy}$ \\
\hline
\end{tabular}

Values were obtained from Figure 2A.

types of therapeutic radiation to determine their potential clinical applications [30-33]. Based on the comparison study using protons in combination with GNPs versus using protons alone, Kim et al. [32] and Polf et al. [33] have shown an over $50 \%$ increase of one-year survival in mice and an approximately $15 \%$ increase in cell killing of prostate cancer cell lines. Recently, Kaur et al. [31] have shown that the dose of carbon ion needed for $90 \%$ cell killing in GNP treated HeLa cells was 2.3 Gy which shows approximately $28 \%$ reduction of dose for GNP treated cells as compared to control cells. To date, however, these studies have been restricted to low-LET radiation or charged particle irradiation. The present study therefore characterized the potential of GNPs as radiosensitizers for high-LET uncharged particle, i.e., neutron, irradiation.

Our results suggested that GNPs enhance the radiotoxicity of neutron radiation more significantly than $\gamma$-ray radiation, as measured by apoptosis, cell cycle arrest, DNA damage, and metastatic potential. To evaluate the radiosensitizing effects of GNPs, the radiosensitivity
A

B
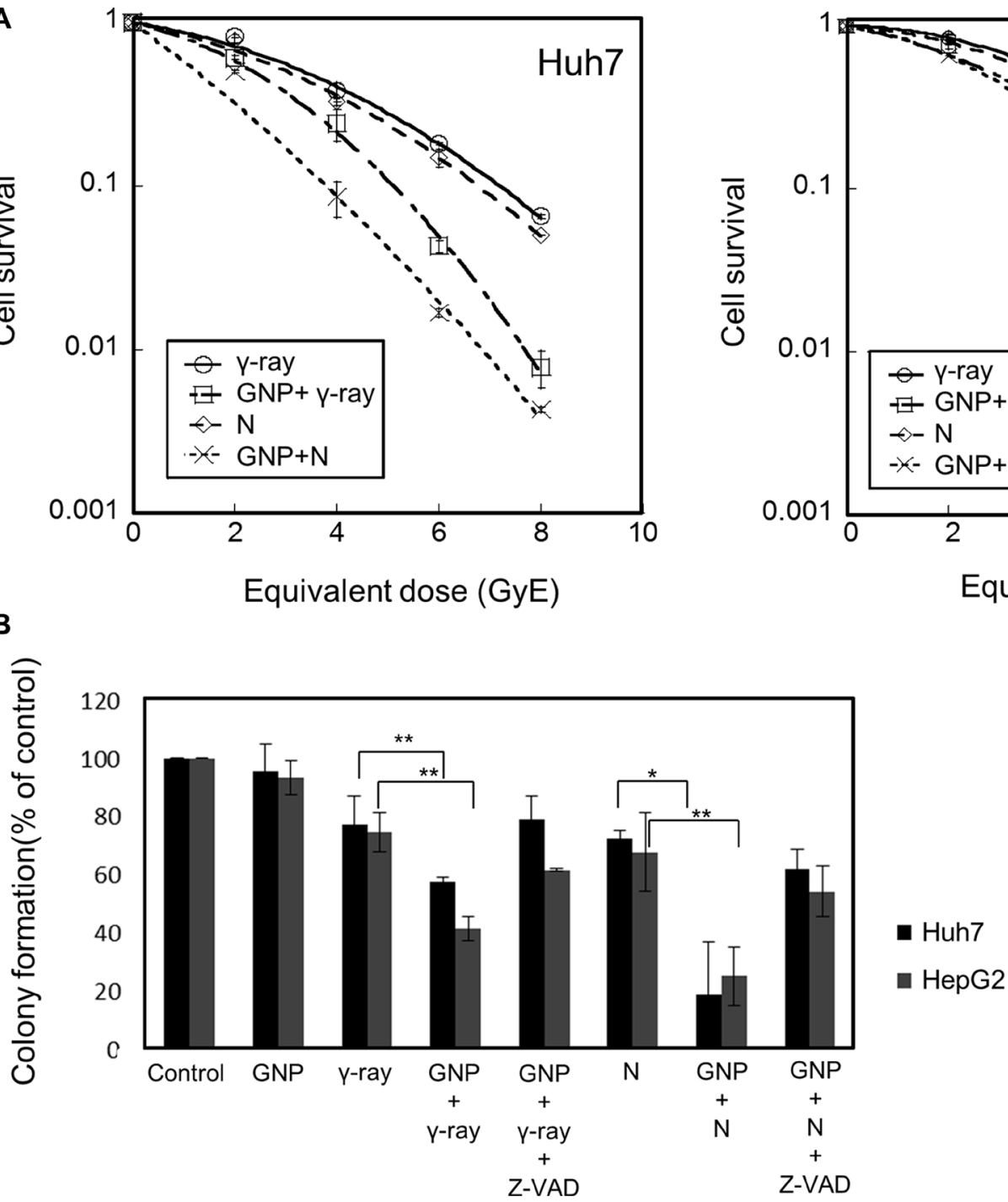
C

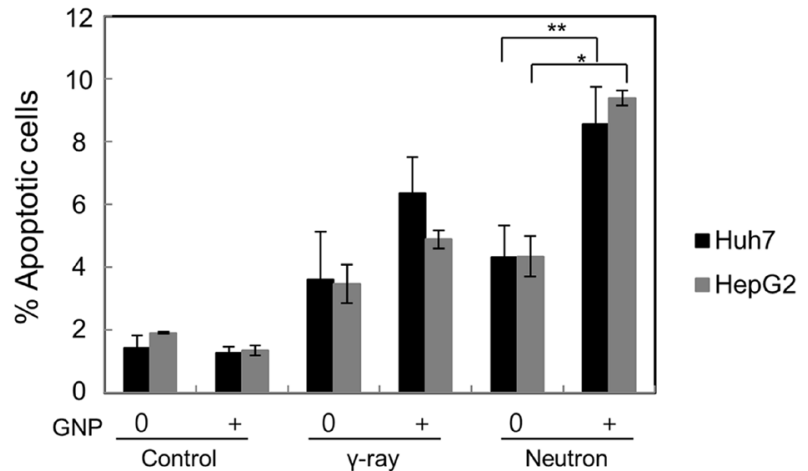

D

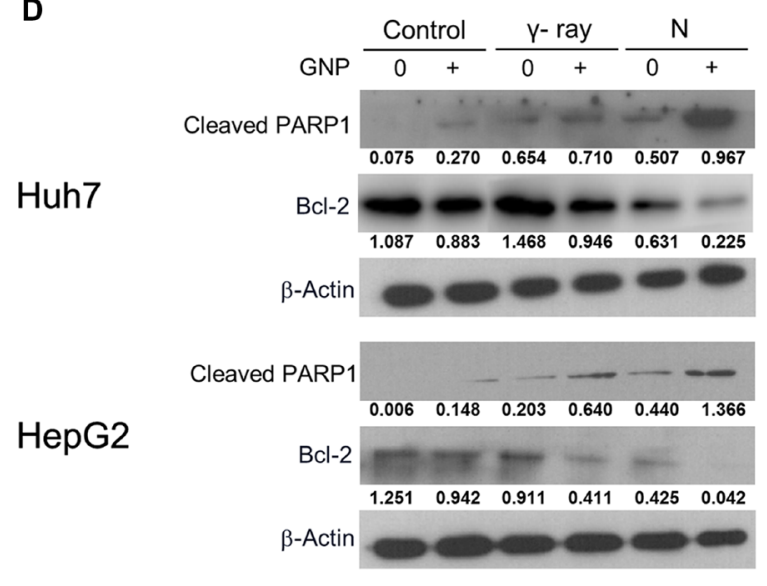

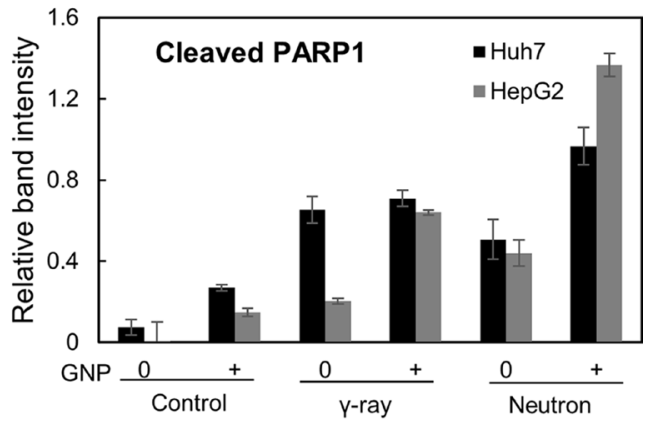

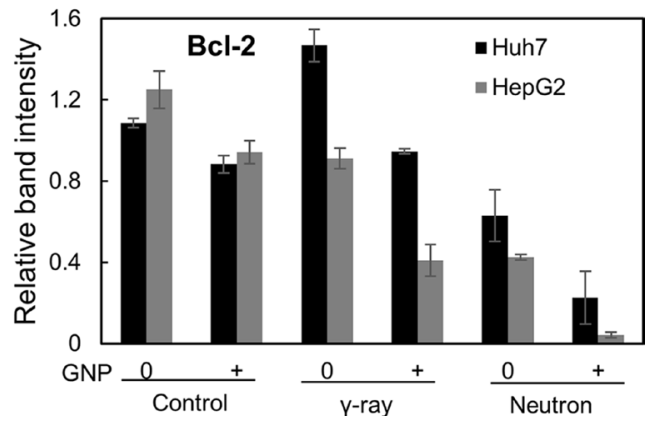

Figure 2: Radiosensitizing effects of gold nanoparticles. (A) Colony-forming assays of Huh7 and HepG2 cells treated with 1 $\mathrm{mM}$ gold nanoparticles and irradiated with $\gamma$-rays and neutrons. Values are the means $\pm \mathrm{SD}$ from three experiments. The $\mathrm{x}$-axis shows the equivalent dose, expressed as GyE (Gray equivalent). (B) Partial abrogation of gold nanoparticle radiosensitization by a pan-caspase inhibitor. Cells were treated with $1 \mathrm{mM}$ gold nanoparticles alone ( $4 \mathrm{~h}$ prior to radiation) or in combination with z-VAD-fmk (10 $\mu \mathrm{M}, 6 \mathrm{~h}$ prior to radiation). The absorbed doses were $5 \mathrm{~Gy}$ for $\gamma$-rays and $5 \mathrm{GyE}$ for neutrons. Effect of $\mathrm{z}$-VAD-fmk on gold nanoparticle radiosensitization was assessed by clonogenic survival assay. Values represent the means \pm SDs of three experiments; ${ }^{*} P<0.05,{ }^{* *} P<0.001$. (C) Apoptosis in Huh7 and HepG2 cells, as measured by annexin V staining $48 \mathrm{~h}$ after irradiation with 5 Gy of $\gamma$-rays or 5 GyE neutrons in the presence or absence of gold nanoparticles. Values represent the means \pm SDs of three experiments; ${ }^{*} P<0.05,{ }^{* *} P<0.001$. (D) Immunoblotting of cell lysates with indicated antibodies. The absorbed doses were 5 Gy for $\gamma$-rays and 5 GyE for neutrons. Band intensities for target proteins were normalized to that for $\beta$-actin. Values represent the means of 3 experiments $\pm \mathrm{SD}$.

enhancement ratio (REF) was calculated as the dose (Gy) of radiation alone divided by the dose of radiation plus GNPs that resulted in $10 \%$ cell survival (D10) (Table 4). While REF values resulting from the addition of GNPs to Huh7 and HepG2 cells were 1.41 and 1.16, respectively, for gamma irradiation, they were 1.80 and 1.35 , respectively, for neutron irradiation. Our results also suggested that GNP alone did not yield foci, even $24 \mathrm{~h}$ after exposure, suggesting that GNP treatment itself did not alter the induction or subsequent disappearance of foci at any time point examined. The combination of GNPs with $\gamma$-ray and neutron irradiation caused much greater DNA damage to HCC cells than $\gamma$-ray and neutron irradiation alone (Table 5), with the REF being higher for neutrons than for $\gamma$-rays.
Low energy photon irradiation of a material containing GNPs has been reported to enhance the radiosensitivity of the material by producing secondary electrons from the nanoparticles due to the high atomic number of gold [6]. These secondary electrons are generated from GNPs by photoelectric effects and Auger cascades, with the latter considered the major source of dose enhancement. Because of their low kinetic energy and low speed, Auger electrons seem to transfer all of their kinetic energy over a short range, locally generating high concentrations of hydroxyl radicals (.OH) and thereby amplifying the effective dose $[34,35]$. Although the exact mechanism underlying the radiosensitizing effect of GNPs has not been firmly established, the biological 
Table 3: Detection of apoptotic cells by annexin V staining on 2 HCC cells

\begin{tabular}{llll}
\hline Cell type & Treatment & \% Apoptotic cells & Ratio \\
\hline & Control & 1.43 & \\
GNP & 1.28 & \\
$\gamma$-ray & 3.62 & \\
$\gamma$-ray+GNP & 6.36 & \\
Nuh7 & 4.33 & 4.97 \\
Neutron & 8.57 & 1.76 \\
& $\gamma$-ray+GNP/GNP & & 6.70 \\
$\gamma$-ray+GNP/ $\gamma$-ray & & 1.98 \\
Neutron+GNP/GNP & & \\
Neutron+GNP/Neutron & & \\
Control & 1.91 & \\
GNP & 1.36 & \\
& $\gamma$-ray & 3.47 & 3.60 \\
HepG2 & 4.89 & 1.41 \\
& Neutron & 4.35 & 6.91 \\
& Neutron+GNP & 9.40 & 2.16 \\
\hline
\end{tabular}

A
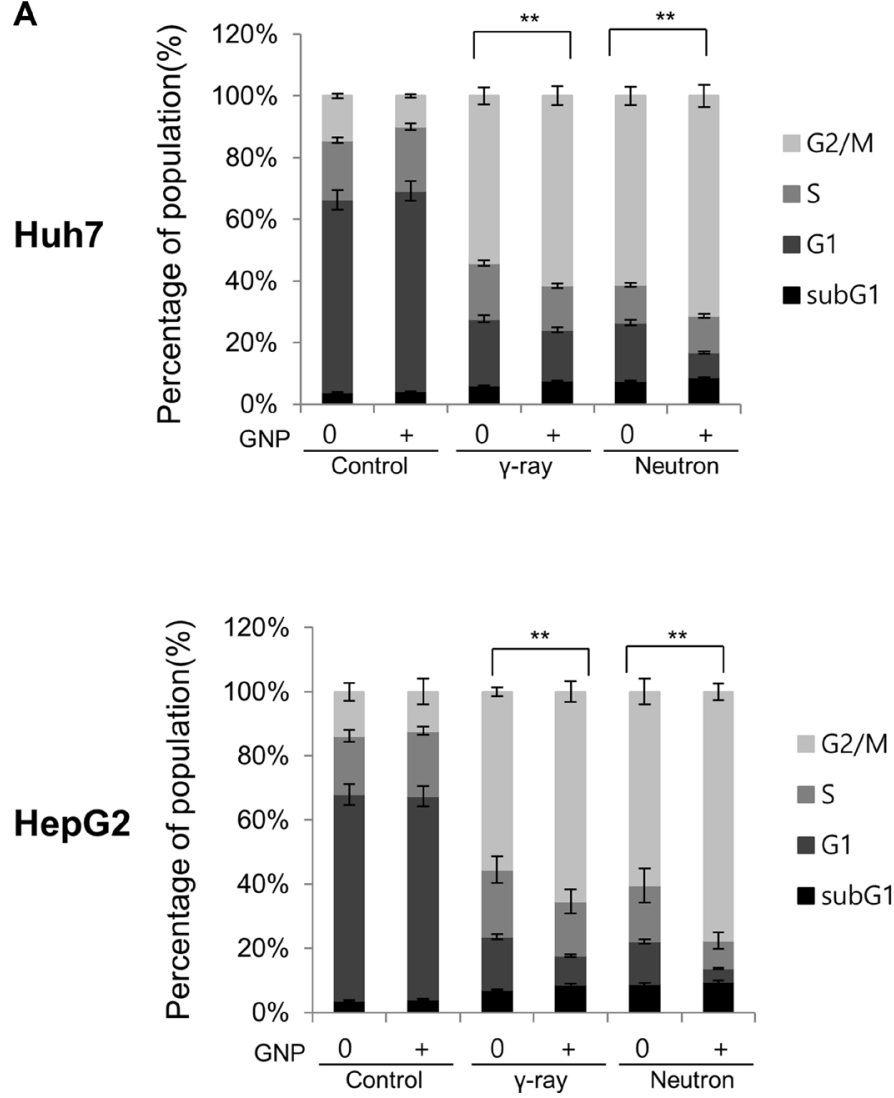

B
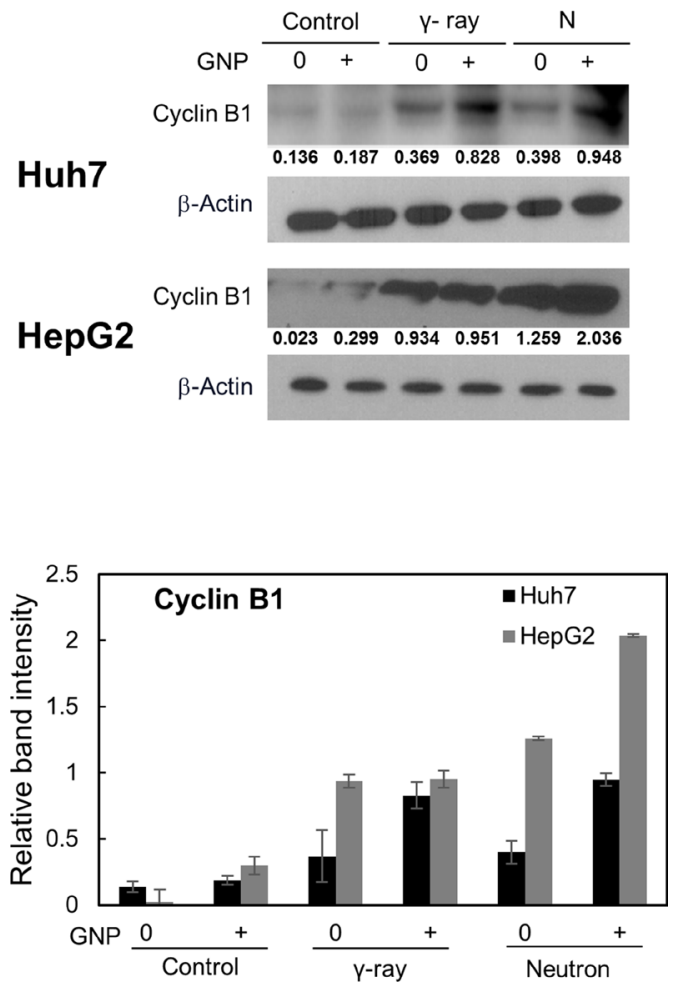

Figure 3: Irradiation in the presence of gold nanoparticles modulates cell cycle progression and expression of cell cycle regulators. (A) Cell cycle distribution, irradiated with $5 \mathrm{~Gy}$ of $\gamma$ and $5 \mathrm{GyE}$ of neutron radiation and (B) expression of cyclin $\mathrm{B} 1$ in Huh7 and HepG2 cells treated with $1 \mathrm{mM}$ gold nanoparticles, irradiated with $5 \mathrm{~Gy}$ of $\gamma$ and $5 \mathrm{GyE}$ of neutron radiation, and incubated for $24 \mathrm{~h}$. Band intensities for target proteins were normalized to that for $\beta$-actin. Values represent the means of 3 experiments \pm SD. 
Table 4: Radiosensitivity enhancement factor (REF) and dose reduction

\begin{tabular}{cccc}
\hline Cell type & Radiation & REF & Dose reduction (\%) \\
\hline \multirow{2}{*}{ Huh7 } & $\gamma$-ray & 1.41 & 29.2 \\
& Neutron & 1.80 & 44.3 \\
\hline \multirow{2}{*}{ HepG2 } & $\gamma$-ray & 1.16 & 13.8 \\
& Neutron & 1.35 & 25.9 \\
\hline
\end{tabular}

Values were obtained from Figure 2A.

REF: ratio of the radiation dose required to kill $90 \%$ of cells in the presence of gold nanoparticles divided by the dose in the absence of gold nanoparticles.

A

Huh7
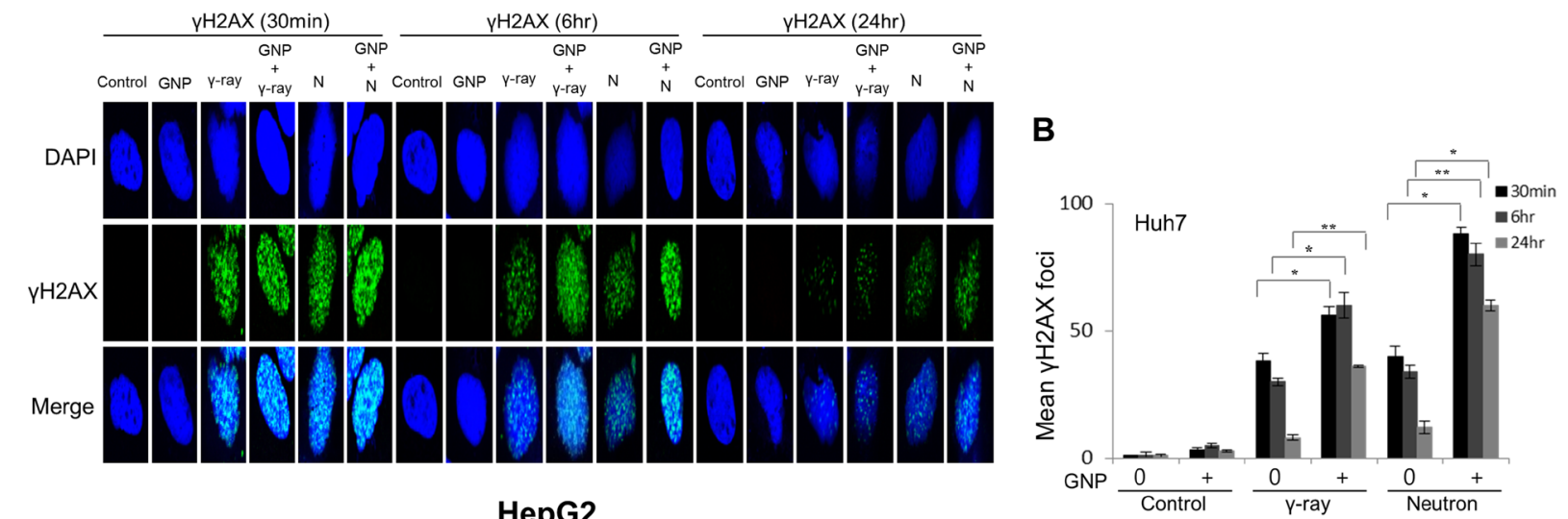

\section{HepG2}
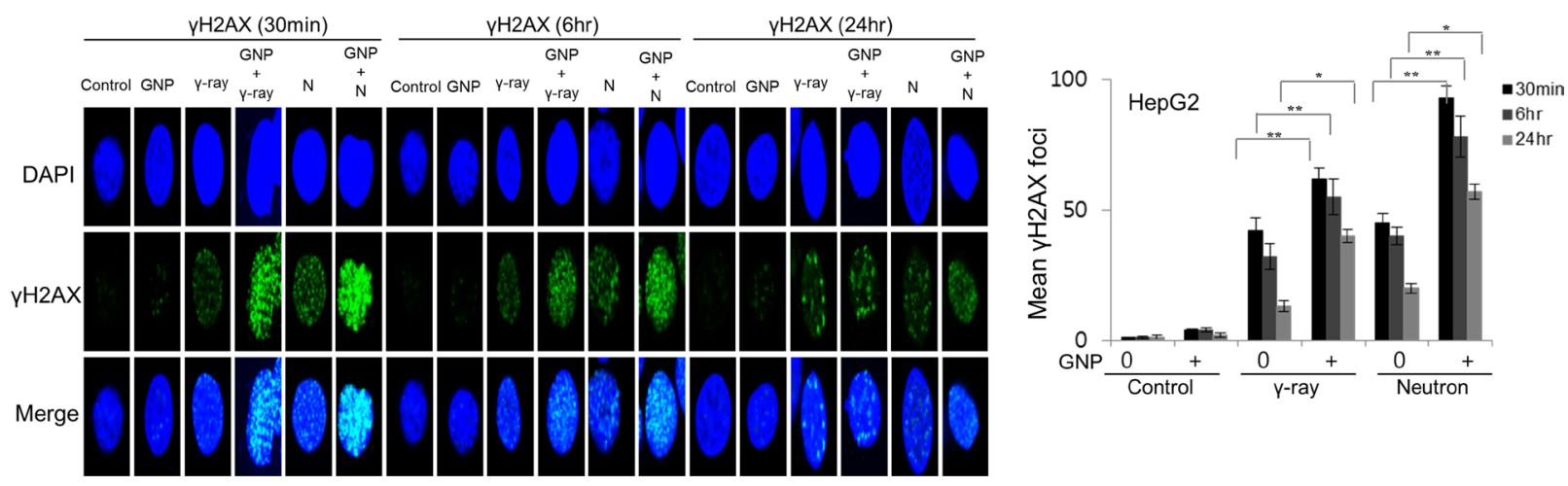

C
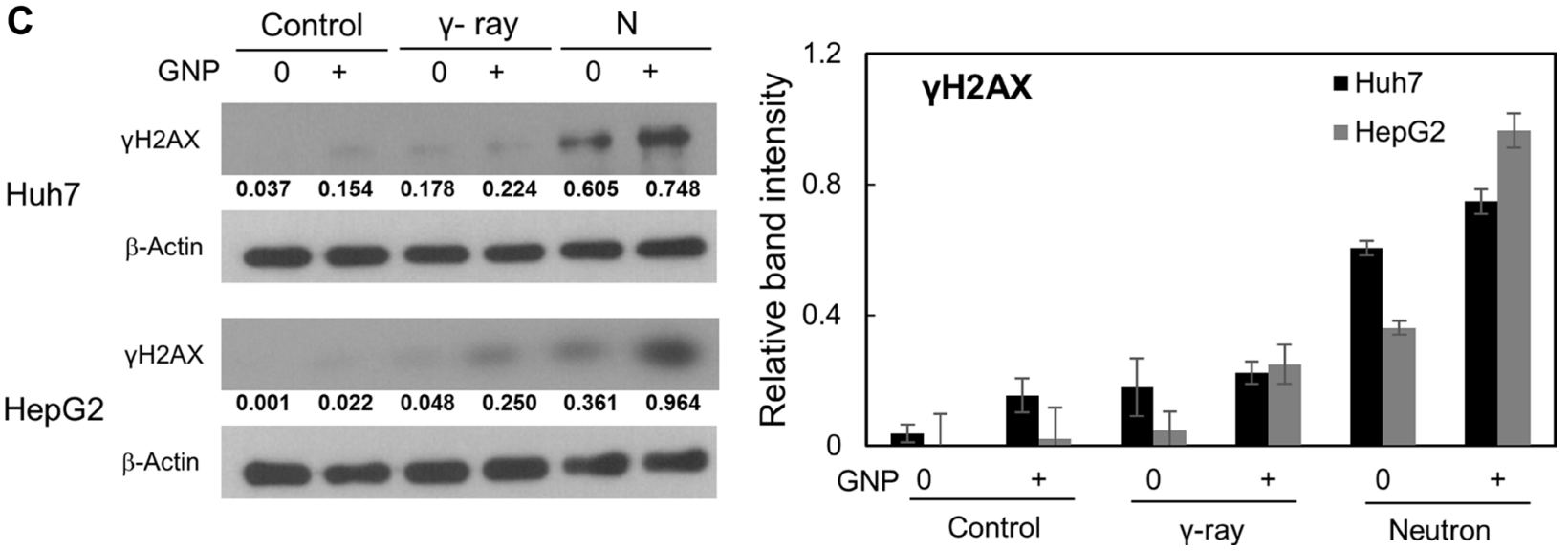

Figure 4: Gold nanoparticles enhance radiation-induced DNA damage. (A, B) Immunocytochemistry staining for phosphorylated $\mathrm{H} 2 \mathrm{AX}$, a marker of DNA damage response, in Huh7 and HepG2 cells exposed to $\gamma$-rays (5 Gy) and neutron radiation (5 GyE) in the absence or presence of gold nanoparticles, assessed $30 \mathrm{~min}, 6 \mathrm{~h}$ and $24 \mathrm{~h}$ after irradiation. (C) Immunoblotting of cell lysates with indicated antibodies. The absorbed doses were $5 \mathrm{~Gy}$ for $\gamma$-rays and $5 \mathrm{GyE}$ for neutrons. Band intensities for target proteins were normalized to that for $\beta$-actin. Values represent the means of 3 experiments $\pm \mathrm{SD}$. 
Table 5: Detection of $\gamma \mathrm{H} 2 \mathrm{AX}$ foci on $2 \mathrm{HCC}$ cells

\begin{tabular}{|c|c|c|c|}
\hline Cell type & Treatment time & Treatment & $\gamma \mathrm{H} 2 \mathrm{AX}$ foci number \\
\hline \multirow{6}{*}{ Huh7 } & \multirow{2}{*}{$30 \mathrm{~min}$} & $\gamma$-ray+GNP $/ \gamma$-ray /GNP & $56 / 38 / 3.5$ \\
\hline & & Neutron+GNP/ Neutron /GNP & $88 / 40 / 3.5$ \\
\hline & \multirow{2}{*}{$6 \mathrm{hr}$} & $\gamma$-ray + GNP $/ \gamma$-ray $/$ GNP & $60 / 30 / 5.0$ \\
\hline & & Neutron+GNP/ Neutron /GNP & $80 / 34 / 5.0$ \\
\hline & \multirow{2}{*}{$24 \mathrm{hr}$} & $\gamma$-ray + GNP $/ \gamma$-ray $/$ GNP & $36 / 8.0 / 3.0$ \\
\hline & & Neutron+GNP/ Neutron /GNP & $60 / 12 / 3.0$ \\
\hline \multirow{6}{*}{ HepG2 } & \multirow{2}{*}{$30 \mathrm{~min}$} & $\gamma$-ray+GNP / $\gamma$-ray /GNP & $62 / 42 / 4.0$ \\
\hline & & Neutron+GNP/ Neutron /GNP & $93 / 45 / 4.0$ \\
\hline & \multirow{2}{*}{$6 \mathrm{hr}$} & $\gamma$-ray + GNP $/ \gamma$-ray /GNP & $55 / 32 / 4.0$ \\
\hline & & Neutron+GNP/ Neutron /GNP & $78 / 40 / 4.0$ \\
\hline & \multirow{2}{*}{$24 \mathrm{hr}$} & $\gamma$-ray + GNP $/ \gamma$-ray /GNP & $40 / 13 / 2.0$ \\
\hline & & Neutron+GNP/ Neutron /GNP & $57 / 20 / 2.0$ \\
\hline
\end{tabular}

effects of neutrons can be explained by the interaction of recoil protons ([36] and references therein). Most (60\%) of the neutrons used in this experiment were fast neutrons (1-20 MeV), with the percentage rising to $80 \%$ percent if relativistic neutrons $(>20 \mathrm{MeV})$ are included. As for the neutron cross section with GNPs in this energy range, hadronic elastic scattering is dominant and, especially for relativistic neutrons, 3-neutron generation cross sections are significantly enhanced [37]. Therefore, by interacting with GNPs, more neutrons will be generated in reaction

A

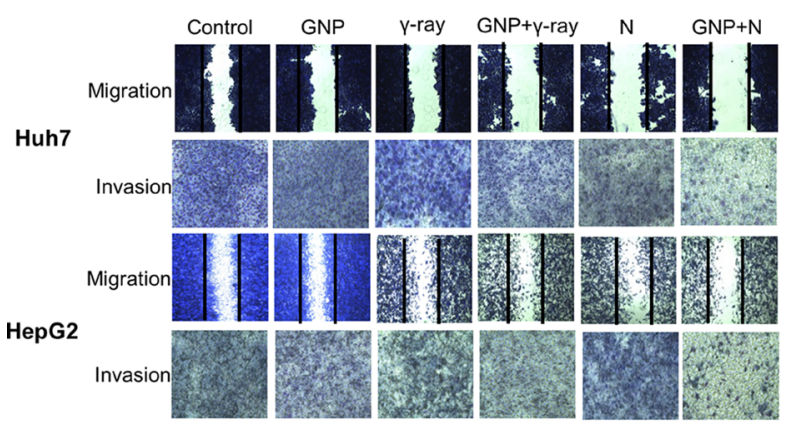

chains, with the increase in neutron population likely contributing to their biological effects. (We are currently expanding this mechanistic investigation by performing a Monte Carlos simulation.)

Although further research is needed to determine whether nanoparticles enhance radiosensitivity to neutron therapy, its applications are highly limited. For example, only three centers in the world currently treat cancer with fast neutrons, perhaps because of a lack of funding and issues of regulatory approval. An alternative approach may

B
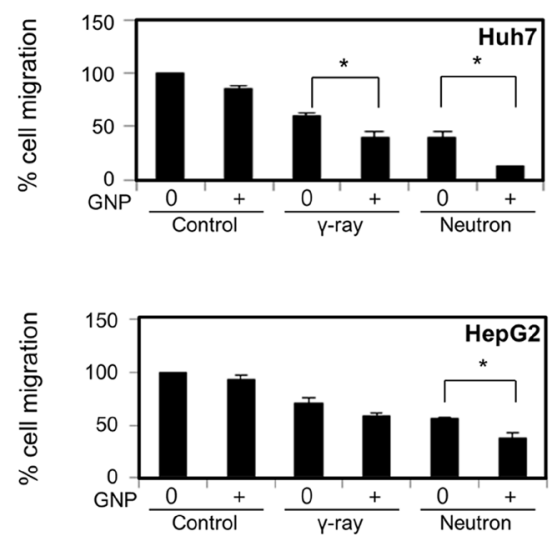

C
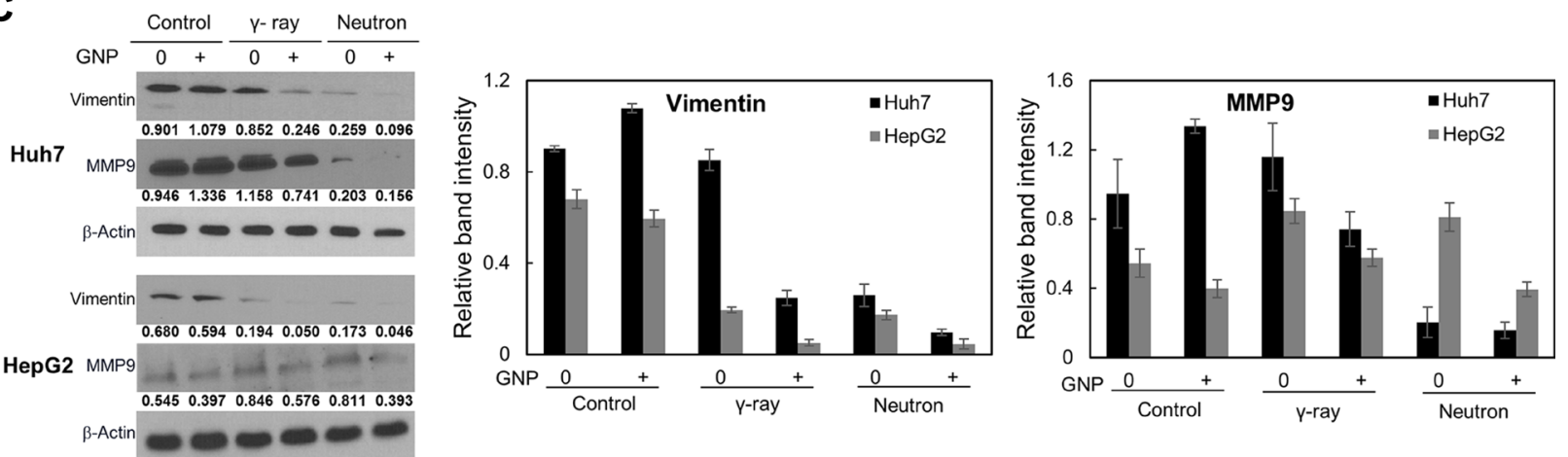

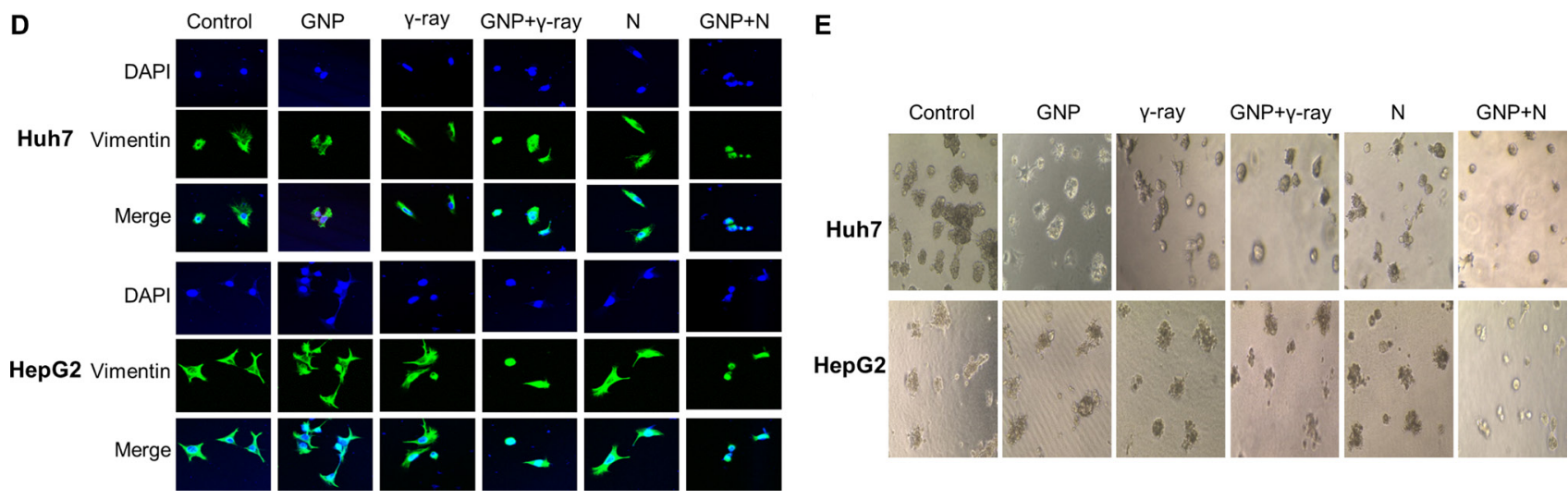

Figure 5: Effect of gold nanoparticles and radiation on cell migration and invasiveness. (A, B) Plates from the scratch assay were photographed, distances between migrating cell fronts were measured, and the fraction of cells that had migrated was calculated (upper). Values are mean $\pm \mathrm{SD}$ of three experiments. Cells exposed to $\gamma$-rays and neutron radiation (5 Gy, 5 GyE). Cell invasion was examined by Matrigel transwell chamber assay (lower). (C) Immunoblotting of cell lysates with indicated antibodies. Cells exposed to $\gamma$-rays and neutron radiation ( $5 \mathrm{~Gy}, 5 \mathrm{GyE}$ ). Band intensities for target proteins were normalized to that for $\beta$-actin. Values represent the means of 3 experiments \pm SD. (D) Immunocytochemistry staining for Vimentin in Huh7 and HepG2 cells exposed to $\gamma$-rays and neutron radiation ( $5 \mathrm{~Gy}, 5 \mathrm{GyE}$ ) in the absence or presence of gold nanoparticles. (E) 3D spheroid growth assay of Huh7 and HepG2 cells treated with gold nanoparticles and radiation for four days. Phase-contrast images indicated that untreated cells formed polarized spheroids, but cells exposed to gold nanoparticles and radiation did not. Cells exposed to $\gamma$-rays and neutron radiation (5 Gy, $5 \mathrm{GyE})$.

be to use other forms of high-LET radiation, such as carbon beams, which are used in Japan and Europe. Investigations are therefore needed to assess whether nanoparticles alter radiosensitivity to carbon beams, and to evaluate the safety of such approaches. Finally, although our results suggest that GNPs have potential as radiosensitizers in neutron therapy, in vivo experiments in animal models are necessary to minimize possible clinical complications.

\section{MATERIALS AND METHODS}

\section{Sample preparation}

Huh7 and HepG2 HCC cells were cultured in RPMI 1640 medium (WelGene, Daegu, Korea), supplemented with $10 \%$ (v/v) fetal bovine serum (Lonza, MD, USA) and $1 \%(\mathrm{v} / \mathrm{v})$ penicillin-streptomycin (Lonza, MD, USA) at $37^{\circ} \mathrm{C}$ in a humidified incubator containing $5 \% \mathrm{CO}_{2}$. Antibodies against $\mathrm{Bcl} 2$, cyclin $\mathrm{B}$, vimentin, and $\beta$-actin were purchased from Santa Cruz Biotechnology (Santa Cruz, CA, USA). Antibodies against cleaved poly(ADPribose) polymerase-1 (PARP1) and MMP9 were obtained from Cell Signaling Technology (Danvers, MA, USA), and antibodies against phosphorylated H2AX from Millipore (Billerica, MA, USA). Gold nanoparticles, about $5 \mathrm{~nm}$ in diameter, were purchased from Cytodiagnostics (Burlington, ON, Canada).

\section{Irradiation and visualization of gold nanoparticles}

HCC cells were seeded on glass cover slips and incubated at $37^{\circ} \mathrm{C}$ for $24 \mathrm{~h}$ in fresh medium with or without gold nanoparticles. Fluorescently labeled ER tracker (Invitrogen, CA, USA), Cy5.5 (Nanocs, Eugene, OR, USA) and DAPI (Thermo Fisher Scientific, MA, USA) were added and colocalization analysis was performed using confocal microscopy [17]. To determine the intracellular distribution of gold nanoparticles, cells were seeded in a culture dish, allowed to adhere for one day, incubated for another $24 \mathrm{~h}$ at $37^{\circ} \mathrm{C}$ with $1 \mathrm{mM}$ gold nanoparticles, and imaged by transmission electron microscopy as described [11].

Cells with/without gold nanoparticles were irradiated with a ${ }^{137} \mathrm{Cs} \gamma$-ray source (Atomic Energy of Canada, Ltd., Ontario, Canada), at a dose of $3.81 \mathrm{~Gy} / \mathrm{min}$, or with fast neutrons (Average energy: $9.8 \mathrm{MeV}$, Approximate LET: $30-40 \mathrm{keV} / \mu \mathrm{m})$ which were produced by bombarding beryllium with ${ }^{9} \mathrm{Be}(\mathrm{p}, \mathrm{n}){ }^{10} \mathrm{~B}$ protons in an $\mathrm{MC}-50$ cyclotron (Scanditronix, Uppsala, Sweden). Gray equivalent (GyE) unit for neutron irradiation states the equivalent biological dose compared to x-ray therapy and was found experimentally using in-vitro study. In all experiments involving gold nanoparticle treated cells, the nanoparticles were added before irradiation and were mixed with culture medium until the end of biological analysis.

\section{Biological analysis}

\section{Colony-forming assays, flow cytometry and apoptosis analysis}

Cells mixed with $1 \mathrm{mM}$ gold nanoparticles were irradiated and incubated for 14 days, as described, and the resulting colonies were stained with $0.4 \%$ crystal violet (Sigma, St. Louis, MO, USA) [38]. Cells were cultured, 
harvested at indicated time points, stained with $1 \mu \mathrm{g} / \mathrm{mL}$ propidium iodide (Sigma, MO, USA), and sorted using a FACScan flow cytometer, with data analyzed by CellQuest (both from Becton Dickinson, CA, USA). Cell apoptosis was assayed as described [12].

\section{Immunocytochemistry and western blotting}

Cells were grown in chambered slides, allowed to attach for one day, irradiated in the presence or absence of gold nanoparticles, and analyzed essentially as described [17]. For western blotting experiments, pretreated cells with/without gold nanoparticles were irradiated with gamma rays or neutrons, incubated for $24 \mathrm{~h}$, lysed with RIPA buffer, and immunoblotted as described [15].

\section{Cell migration, transwell chamber invasion and 3D spheroid growth assays}

To assess cell migration, cells were grown to $\sim 90 \%$ confluency in 6-well plates, and the layer of cells was finely scratched with a sterile pipette tip. Invasion was measured in vitro using transwell chambers, according to the manufacturer's protocol. Cells that passed through Matrigel-coated membranes were stained with a crystal violet solution supplied in the transwell invasion assay kit (Chemicon, Millipore, MA, USA) and photographed after $24 \mathrm{~h}$. For 3D-spheroid growth assays, cells suspended in $2.5 \%$ Matrigel were added to 48 -well plates coated with Matrigel, and allowed to grow for up to 4 days.

\section{Statistical analysis}

Statistical significance was determined by Student's $t$-test. Differences were considered significant at $p$ values less than 0.05 and 0.001 .

\section{Author contributions}

M.Y., M.K. and E.K. designed the idea, the experimental setup and wrote the manuscript. H.S., S.Y., S.S., K.C., Y.J. and J.S. performed the experiments. M.Y and E.K analysed the data. All authors read and approved the final version of the manuscript.

\section{CONFLICTS OF INTEREST}

The authors declare no conflicts of interests.

\section{FUNDING}

This work was supported by a National Research Foundation of Korea (NRF) grant (No.NRF2017K2A9A2A08000212, NRF-2015M2A2A7A02045273) funded by the Korean government (MSIP) and a grant from the Korea Institute of Radiological and Medical Sciences
(KIRAMS), funded by Ministry of Science, ICT and Future Planning, Republic of Korea (1711042677, 1711045548, 1711045553, 1711045555/505432017).

\section{REFERENCES}

1. Jemal A, Bray F, Center MM, Ferlay J, Ward E, Forman D. Global Cancer Statistics. CA Cancer J Clin. 2011; 61:69-90. https://doi.org/10.3322/caac.20107.

2. Lau WY, Lai ECH, Lau SHY. The current role of neoadjuvant/adjuvant/chemoprevention therapy in partial hepatectomy for hepatocellular carcinoma: a systematic review. Hepatobiliary Pancreat Dis Int. 2009; 8:124-33.

3. Bosch FX, Ribes J, Diaz M, Cleries R. Primary liver cancer: Worldwide incidence and trends. Gastroenterology. 2004 (Suppl 1); 127:S5-S16. https://doi.org/10.1053/j.gastro.2004.09.011.

4. Poon RTP, Fan ST, Tsang FHF, Wong J. Locoregional therapies for hepatocellular carcinoma: A critical review from the surgeon's perspective. Ann Surg. 2002; 235:466- 86 . https://doi.org/10.1097/00000658-200204000-00004.

5. Poggi MM, Coleman CN, Mitchell JB. Sensitizers and protectors of radiation and chemotherapy. Curr Probl Cancer. 2001; 25:334-411. https://doi.org/10.1067/ mcn.2001.120122.

6. Lin YT, McMahon SJ, Scarpelli M, Paganetti H, Schueman J. Comparing gold nano-particle enhanced radiotherapy with protons, megavoltage photons and kilovoltage photons: a Monte Carlo simulation. Phys Med Biol. 2014; 59:7675-89. https://doi. org/10.1088/0031-9155/59/24/7675.

7. Wambersie A, Richard F, Breteau N. Development of FastNeutron Therapy Worldwide - Radiobiological, Clinical and Technical Aspects. Acta Oncol. 1994; 33:261-74.

8. Theron T, Slabbert J, Serafin A, Bohm L. The merits of cell kinetic parameters for the assessment of intrinsic cellular radiosensitivity to photon and high linear energy transfer neutron irradiation. Int J Radiat Oncol Biol Phys. 1997; 37:423-8. https://doi. org/10.1016/S0360-3016(96)00533-0.

9. Douglas JG, Koh WJ, Austin-Seymour M, Laramore GE. Treatment of salivary gland neoplasms with fast neutron radiotherapy. Arch Otolaryngol Head Neck Surg. 2003; 129:944-8. https://doi.org/10.1001/ archotol.129.9.944.

10. Liauw SL, Connell PP, Weichselbaum RR. New Paradigms and Future Challenges in Radiation Oncology: An Update of Biological Targets and Technology. Sci Transl Med. 2013; 5:173sr2. https://doi.org/ARTN 173sr210.1126/ scitranslmed.3005148.

11. Cai W, Gao T, Hong H, Sun J. Applications of gold nanoparticles in cancer nanotechnology. Nanotechnol Sci Appl. 2008; 1:17-32.

12. Boisselier E, Astruc D. Gold nanoparticles in nanomedicine: preparations, imaging, diagnostics, therapies and toxicity. Chemical Society Reviews. 2009; 38:1759-82. https://doi. org/10.1039/b806051g.

13. Dreaden EC, Austin LA, Mackey MA, El-Sayed MA. Size matters: gold nanoparticles in targeted cancer drug delivery. Ther Deliv. 2012; 3:457-78. 
14. Jain S, Hirst DG, O'Sullivan JM. Gold nanoparticles as novel agents for cancer therapy. Br J Radiol. 2012; 85:101-13. https://doi.org/10.1259/ bjr/59448833.

15. Hainfeld JF, Dilmanian FA, Slatkin DN, Smilowitz HM. Radiotherapy enhancement with gold nanoparticles. J Pharm Pharmacol. 2008; 60:977-85. https:// doi. org/10.1211/jpp.60.8.0005.

16. Alkilany AM, Murphy CJ. Toxicity and cellular uptake of gold nanoparticles: what we have learned so far? J Nanopart Res. 2010; 12:2313-33. https://doi. org/10.1007/s11051010-9911-8.

17. Chithrani DB, Jelveh S, Jalali F, van Prooijen M, Allen C, Bristow RG, Hill RP, Jaffray DA. Gold Nanoparticles as Radiation Sensitizers in Cancer Therapy. Radiat Res. 2010; 173:719-28. https://doi.org/10.1667/ RR1984.1.

18. Delong RK, Reynolds CM, Malcolm Y, Schaeffer A, Severs T, Wanekaya A. Functionalized gold nanoparticles for the binding, stabilization, and delivery of therapeutic DNA, RNA, and other biological macromolecules. Nanotechnol Sci Appl. 2010; 3:53-63. https://doi. org/10.2147/NSA.S8984.

19. Nagasawa H, Keng P, Harley R, Dahlberg W, Little JB. Relationship between Gamma-Ray-Induced G(2)/M Delay and Cellular Radiosensitivity. Int J Rad Biol. 1994; 66:373-9. https://doi. org/10.1080/09553009414551311.

20. Bernhard EJ, Maity A, Muschel RJ, Mckenna WG. Effects of Ionizing-Radiation on Cell-Cycle Progression - a Review. Radiat Environ Biophys. 1995; 34:79-83. https:// doi.org/10.1007/Bf01275210.

21. Fournier C, Taucher-Scholz G. Radiation induced cell cycle arrest: an overview of specific effects following high-LET exposure. Radiother Oncol. 2004 (Suppl 2); 73:S119-S22. https://doi.org/10.1016/S0167-8140(04)80031-8.

22. Ghosh P, Han G, De M, Kim CK, Rotello VM. Gold nanoparticles in delivery applications. Adv Drug Deliv Rev. 2008; 60:1307-15. https://doi. org/10.1016/j.addr.2008.03.016.

23. Ferrari M. Cancer nanotechnology: Opportunities and challenges. Nat Rev Cancer. 2005; 5:161-71. https://doi. org/10.1038/nrc1566.

24. Paciotti GF, Myer L, Weinreich D, Goia D, Pavel N, McLaughlin RE, Tamarkin L. Colloidal gold: A novel nanoparticle vector for tumor directed drug delivery. Drug Deliv. 2004; 11:169-83. https://doi. org/10.1080/10717540490433895.

25. Song K, Xu P, Meng YD, Geng F, Li J, Li Z, Xing J, Chen J, Kong BH. Smart gold nanoparticles enhance killing effect on cancer cells. Int J Oncol. 2013; 42:597-608. https://doi. org/10.3892/ijo.2012.1721.

26. Cho SH. Estimation of tumour dose enhancement due to gold nanoparticles during typical radiation treatments: a preliminary Monte Carlo study. Phys Med Biol. 2005; 50:N163-N73. https://doi.org/10.1088/0031- 9155/50/15/N01.

27. Lechtman E, Mashouf S, Chattopadhyay N, Keller BM, Lai P, Cai Z, Reilly RM, Pignol JP. A Monte Carlo-based model of gold nanoparticle radiosensitization accounting for increased radiobiological effectiveness. Phys Med Biol. 2013; 58:3075-87. https://doi. org/10.1088/00319155/58/10/3075.

28. Liu CJ, Wang $\mathrm{CH}$, Chen ST, Chen HH, Leng WH, Chien CC, Wang CL, Kempson IM, Hwu Y, Lai TC, Hsiao M, Yang CS, Chen YJ, et al. Enhancement of cell radiation sensitivity by pegylated gold nanoparticles. Phys Med Biol. 2010; 55:931-45. https:// doi.org/10.1088/00319155/55/4/002.

29. Van den Heuvel F, Locquet JP, Nuyts S. Beam energy considerations for gold nano-particle enhanced radiation treatment. Phys Med Biol. 2010; 55:4509-20. https://doi. org/10.1088/0031-9155/55/16/S06.

30. Hainfeld JF, Slatkin DN, Smilowitz HM. The use of gold nanoparticles to enhance radiotherapy in mice. Phys Med Biol. 2004; 49:N309-N15.

31. Kaur H, Avasthi DK, Pujari G, Sarma A. Radiosensitizing effect of gold nanoparticles in carbon ion irradiation of human cervical cancer cells. AIP Conference Proceedings. 2013; 1530:1, 205-210. https://doi.org/10.1063/1.4812924.

32. Kim JK, Seo SJ, Kim HT, Kim KH, Chung MH, Kim KR, Ye SJ. Enhanced proton treatment in mouse tumors through proton irradiated nanoradiator effects on metallic nanoparticles. Phys Med Biol. 2012; 57. https://doi.org/Artn 830910.1088/0031-9155/57/24/8309.

33. Polf JC, Bronk LF, Driessen WHP, Arap W, Pasqualini R, Gillin M. Enhanced relative biological effectiveness of proton radiotherapy in tumor cells with internalized gold nanoparticles. Appl Phys Lett. 2011; 98:193702. https://doi. org/Artn19370210.1063/1.3589914.

34. Butterworth KT, McMahon SJ, Currell FJ, Prise KM. Physical basis and biological mechanisms of gold nanoparticle radiosensitization. Nanoscale. 2012; 4:4830-8. https://doi.org/10.1039/c2nr31227a.

35. Balagurumoorthy $\mathrm{P}$, Chen $\mathrm{K}$, Adelstein SJ, Kassis AI. Auger electron-induced double-strand breaks depend on DNA topology. Radiat Res. 2008; 170:70-82. https://doi. org/10.1667/Rr1072.1.

36. Shmatov ML. Potential to raise the efficiency of neutron and neutron-photon therapy using metal nonradioactive nanoparticles. Physics of Particles and Nuclei Letters. 2016; 13:514-20. https://doi.org/10.1134/s1547477116040117.

37. Chadwick MB, Herman M, Obložinský P, Dunn ME, Danon Y, Kahler AC, Smith DL, Pritychenko B, Arbanas G, Arcilla R, Brewer R, Brown DA, Capote R, et al. ENDF/ B-VII.1 Nuclear Data for Science and Technology: Cross Sections, Covariances, Fission Product Yields and Decay Data. Nuclear Data Sheets. 2011; 112:2887-996. https://doi. org/10.1016/j. nds.2011.11.002.

38. Eom KY, Wu HG, Park HJ, Huh SN, Ye SJ, Lee DH, Park SW. Evaluation of biological characteristics of neutron beam generated from MC50 cyclotron. J Korean Soc Ther Radiol Oncol. 2006; 24:280-4. 